\title{
Selenium Status in an Iodine Deficient Population of the West Ivory Coast
}

\author{
Josiane Arnaud ${ }^{1)}$, Denis Malvy' ${ }^{2)}$, Marie-Jeanne Richard ${ }^{1)}$, \\ Henri Faure ${ }^{1)}$ and André Chaventré ${ }^{3)}$
}

\author{
1) Department of Integral Biology, CHUG, Grenoble, France \\ 2) Centre René Labusquière and INSERM U 330, University Victor Ségalen - Bordeaux 2, Bordeaux, France \\ 3) Laboratory for Anthropology and Genetic Demography, University Victor Ségalen - Bordeaux 2, France
}

\begin{abstract}
Selenium is an essential trace element which is part of the active site of seleno-dependent glutathione peroxidase and type 1 deiodinase. Therefore, it plays a key role in thyroid hormone metabolism. The present work was undertaken in order to evaluate selenium status in two Ivory Coast populations: the first with high (Glanlé) and the second with low (Abidjan) prevalence of iodine deficiency. Selenium, glutathione peroxidase, glutathione reductase, glutathione and diglutathione were determined in blood and/or urine. In plasma and erythrocytes, selenium and glutathione peroxidase were dramatically low in Glanlé. Compared to Abidjan, selenium, glutathione peroxidase, vitamin E and riboflavin status were decreased whereas diglutathione was increased in Glanlé. The results clearly demonstrate a selenium deficiency and suggest an oxidant stress in Glanlé. Causes and consequences of this selenium deficiency and oxidant stress remain to be determined. J Physiol Anthropol 20 (2): 81-84, 2001 http:// www.jstage.jst.go.jp/en/
\end{abstract}

Keywords: selenium, deficiency, humans, iodine status

\section{Introduction}

Selenium was discovered in 1817 by Berzelius. It was considered for a long time to be a toxic element for humans and animals. Its essential role in animals was proven in 1957. Briefly, this trace element may prevent cancer, heart diseases and toxic manifestations due to xenobiotics or toxic elements, it delays the ageing process and enhances humoral, cell-mediated and non-specific immunity (Nève and Thérond, 1991; Nève, 1991a).

There is a large variation in selenium concentration and availability in soil and food all over the world. These differences are explained by differences in soil composition (basalt has been reported to contain more selenium than granite (Goyens et al., 1987)), soil acidity and redox function (Nève and Thérond, 1991), both of which modify selenium availability for plants. Therefore, human selenium dietary intake and status differ considerably among geographical area (Table 1). Contrary to other trace elements, i.e. iron, zinc or copper, selenium is highly available from foods. Moreover, selenium bioavailability from foods of plant origin is higher than from animal products (Goyens et al., 1987; Combs, 1988; Fairweather-Tait, 1997). Therefore, family income is not a significant determinant of selenium status.

Selenium is part of the active site of seleno-dependent glutathione peroxidase (GPX) and type 1 deiodinase (Larsen and Berry, 1995; Kölrle, 1995; Diplock, 1992; Dumont et al., 1994). Therefore, selenium status plays a key role in thyroid hormone metabolism. Interaction between iodine and selenium biological function greatly depends on the status of these two trace elements. Review articles have been written on that topic (Larsen and Berry, 1995; Kölrle, 1995). Combined selenium and iodine deficiency causes an irreversible loss of thyroid function. Iodine deficiency is a necessary condition of endemic goitre. However, the lack of type 1 desiodinase and increase in oxygen toxicity, as a consequence of selenium deficiency, contribute to irreversible thyroid damages (Goyens et al., 1987; Vanderpas et al., 1993; Untoro et al., 1999). Thyroid metabolism modifications during the association of selenium and iodine deficiencies are summarised in Fig. 1. Moreover, in Africa, thiocyanate, originating from cassava contributes also to goitrogenesis and could amplify the effects of selenium deficiency (Goyens et al., 1987; Levander, 1982).

In the West part of Ivory Coast Republic, goitre and cretinism prevalence is high (Kouamé et al., 1998; 
Table 1 Selenium dietary intake and status in different countries

\begin{tabular}{lccc}
\hline \multicolumn{1}{c}{ Countries } & $\begin{array}{c}\text { Se intake } \\
\mu \mathrm{g} / \mathrm{d}\end{array}$ & $\begin{array}{c}\text { Serum Se } \\
\mu \mathrm{mol} / \mathrm{l}\end{array}$ & $\begin{array}{c}\text { Whole blood Se } \\
\mu \mathrm{mol} / \mathrm{l}\end{array}$ \\
\hline China (Keshan area) & 11 & $<0.30$ & $0.13-0.38$ \\
New Zealand & $28-32$ & $0.38-0.63$ & $0.57-1.14$ \\
Finland (Before supplementation) & 30 & $0.38-0.89$ & $0.63-1.01$ \\
Belgium & $50-60$ & $0.76-1.33$ & $1.20-2.09$ \\
France & $35-48$ & $0.70-1.35$ & \\
The United States of America & $60-220$ & $1.27-2.53$ & $1.90-2.85$ \\
Canada & $110-220$ & $1.27-2.53$ & $1.90-3.16$ \\
Venezuela & $>220$ & $1.16-1.45$ & $>4.43$ \\
\hline
\end{tabular}

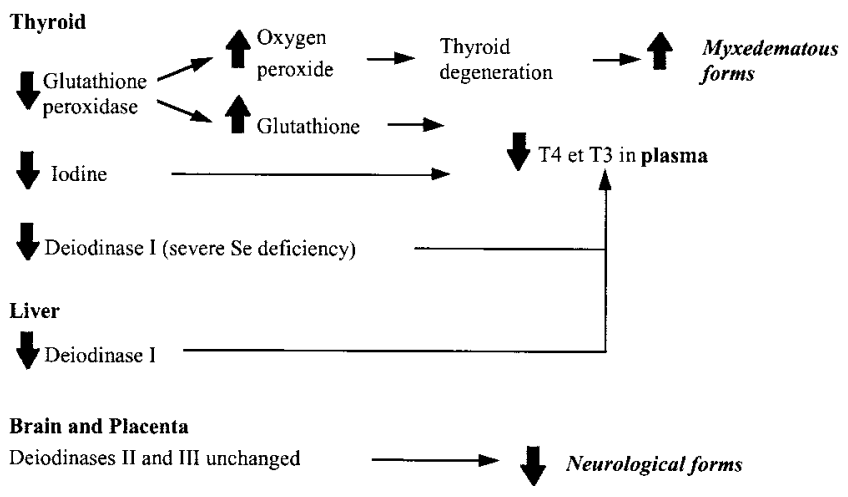

Fig. 1 Coupled iodine and selenium deficiencies and thyroid metabolism

Zimmermann et al., 2000) but blood serum thyroid hormones remain in the international reference ranges (Kouamé et al., 1998). The present study was conducted in order to evaluate selenium status in a village (Glanlé) located in the west part of Ivory Coast Republic and in its capital (Abidjan).

\section{Material and Methods}

The subjects recruited for this study included 50 subjects living in the west part of Ivory Coast Republic (Glanlé) and 47 apparently healthy control subjects living in the capital of Ivory Coast Republic (Abidjan). In the first area, the prevalence of goitre and cretinism is high whereas in the second area, goitre and cretinism are not encountered. Glanlé is in a mountain area, whereas Abidjan is close to the sea. In Glanlé, families produce their own foods, whereas in Abidjan, consumed foods could be produced outside.

Blood was collected by venipuncture in Vacutainer ${ }^{\circledR}$ tubes containing heparin as anticoagulant. Samples were immediately stored in a refrigerated box and kept refrigerated until sample treatment. For glutathione determination, one volume of whole blood was deproteinized with 9 volumes of $6 \%(\mathrm{w} / \mathrm{v}$ ) metaphosphoric acid within 2 hours. Supernatant was isolated by centrifugation at $4000 \mathrm{rd} / \mathrm{min}$ for $20 \mathrm{~min}$ and stored in cryovials at $-70^{\circ} \mathrm{C}$ within one hour and kept frozen until analysis. The other blood sample was centrifuged at 4000 $\mathrm{rd} / \mathrm{min}$ for $20 \mathrm{~min}$ at $4^{\circ} \mathrm{C}$. Erythrocytes and plasma were separated and frozen at $-70^{\circ} \mathrm{C}$ until analysis. Urine was collected in polypropylene vials in the morning (7.30-9.30 a.m.). Aliquot was frozen at $-70^{\circ} \mathrm{C}$ until analysis.

Selenium was determined in plasma (P Se), erythrocytes (E Se) and urine (U Se), after sample dilution, using electrothermal atomic absorption spectrometry with Zeeman background correction. Seleno-glutathione peroxidase was performed in plasma (P GPX) and erythrocytes (E GPX) by a modified method of Gunzler et al. (Gunzler et al., 1974) using a RA 1000 autoanalyzer. Glutathione reductase was determined in erythrocytes ( $\mathrm{E}$ GR) using the method of Thurnam and Rathakette (Thurnham and Rathakette, 1982). Whole blood total glutathione (GSHt), glutathione (GSHr) and diglutathione (GSSG) were determined using the method of Akerboom and Sies (Akerboom and Sies, 1981). Plasma vitamin E and retinol determinations were performed by high performance liquid chromatography (Arnaud et al., 1991). Riboflavin status was assessed by erythrocyte glutathione reductase activation coefficient (E GR AC) (Nichoalds et al., 1974; Bayoumi and Rosalki, 1976). Plasma albumin measurements were performed by immunoprecipitation and urinary creatinin was determined by Jaffe's method using a Hitachi 917 autoanalyzer. Accuracy and precision of analysis were ckecked using control materials.

\section{Results}

Results are indicated in Table 2. Selenium status was lower in Glanle than in Abidjan as demonstrated by the statistically significant lower levels in plasma, erythrocytes and urinary selenium as well as the decrease in glutathione peroxidase activity in plasma and erythrocytes. Moreover, when compared to international reference ranges, the population of Glanlé was selenium deficient. Albumin and vitamin E status were lower in Glanlé than in Abidjan, whereas diglutathione and total glutathione were higher. However, the albumin and vitamin E results remained 
Table 2 Biological results obtained in 2 Ivory Coast Republic populations with high (Glanlé) and low (Abidjan) prevalence of iodine deficiency

\begin{tabular}{lccc}
\hline \multicolumn{1}{c}{ Parameters } & Abidjan & Glanlé & P \\
& $\mathrm{n}=47$ & $\mathrm{n}=50$ & (Student t test) \\
\hline Plasma Selenium (P Se), $\mu$ mol/l & $1.25 \pm 0.20$ & $0.40 \pm 0.15$ & $<0.0001$ \\
Erythrocyte Selenium (E Se), $\mu$ mol/l & $2.97 \pm 1.06$ & $0.77 \pm 0.33$ & $<0.0001$ \\
E Se/P Se & $2.39 \pm 0.89$ & $2.00 \pm 0.50$ & 0.0130 \\
Urinary Selenium (U Se), $\mu$ mol/l & $0.80 \pm 0.46$ & $0.20 \pm 0.11$ & $<0.0001$ \\
U Se, $\mu$ mol/mmol creatinine. & $42 \pm 17$ & $8 \pm 4$ & $<0.0001$ \\
Plasma Glutathione Peroxidase, UI/l & $322 \pm 45$ & $173 \pm 49$ & $<0.0001$ \\
Erythrocyte Glutathione Peroxidase, UI/g Hb & $61 \pm 21$ & $21 \pm 7$ & $<0.0001$ \\
Total Glutathione, $\mu$ mol/l & $689 \pm 197$ & $849 \pm 253$ & 0.0008 \\
Diglutathione (GSSG), $\mu$ mol/l & $21 \pm 7$ & $64 \pm 38$ & $<0.0001$ \\
Glutathione (GSHr), $\mu$ mol/l & $648 \pm 188$ & $722 \pm 229$ & $\mathrm{NS}$ \\
GSHr/GSSG & $33 \pm 10$ & $15 \pm 8$ & $<0.0001$ \\
Erythrocyte Glutathione Reductase (E GR), UI/g Hb & $2.18 \pm 1.15$ & $2.21 \pm 1.06$ & $\mathrm{NS}$ \\
E GR Activation Coefficient & $1.68 \pm 0.43$ & $1.95 \pm 0.45$ & 0.0028 \\
Vitamin E, $\mu$ mol/l & $21.5 \pm 4.3$ & $17.7 \pm 3.6$ & $<0.0001$ \\
Albumin, g/l & $44 \pm 6$ & $40 \pm 5$ & $<0.0001$ \\
Retinol, $\mu$ mol/l & $1.66 \pm 0.44$ & $1.57 \pm 0.55$ & $\mathrm{NS}$ \\
\hline
\end{tabular}

Results are expressed as mean \pm 1 standard deviation.

within the international reference ranges. On the contrary, riboflavin status was marginal and total glutathione was low both in Abidjan and Glanlé.

\section{Discussion}

The village of Glanlé was of interest because of the high incidence of goitre but also because most of the families produced much of their own foods. On the contrary, Abidjan was selected because of the low incidence of goitre, its seaside location and availability of food items produced outside the country.

Our results clearly demonstrate a selenium deficiency in the village of Glanlé (Van den berg et al., 1993). All selenium indices were dramatically lower in the Glanlé inhabitants than in the Abidjan residents. Moreover, 23 out of the 50 subjects living in Glanle had plasma selenium concentration under $0.35 \mu \mathrm{mol} / \mathrm{l}$, the cut-off of severe selenium deficiency (Van den berg et al., 1993). Finally, in Glanlé, plasma selenium concentration was comparable to those reported in selenium deficient area i.e. China or New Zealand (Table 1). On the contrary, selenium status in Abidjan was adequate (Thorling et al., 1986; Nève, 1991b). Moreover, only one out of the 47 subjects had plasma selenium under $0.75 \mu \mathrm{mol} / \mathrm{l}$, considered to reflect marginal selenium status (Van den berg et al., 1993). Selenium deficiency in Glanlé is not the consequence of protein malnutrition as plasma albumin concentrations are in the international reference range. However, albumin was lower in Glanlé subjects than in the Abidjan residents. Unfortunately, no information about the selenium content of the soil and food of Glanlé is available. The higher selenium status of the Abidjan population could be explained by difference in their consumption habits and by the availability of foods from different origins. A possible hypothesis for the very poor selenium status in Glanlé population could be attributed to genetic factors.

Low GPX activity in Glanlé could be explained by the decrease in selenium status but also in vitamin $\mathrm{E}$ and riboflavin status (Golden and Ramdath, 1987; Kuang, 1991). However, glutathione reductase activity was equal in Glanlé and Abidjan. Plasma vitamin E, selenium and riboflavin status and GSH/GSSG ratio were significantly lower in Glanlé than in Abidjan. These results suggest an oxidant stress in Glanlé (Golden and Ramdath, 1987; Kuang, 1991; Richard, 1996).

According to reference ranges of our laboratory (Arnaud and Preziosi, 1994), glutathione concentrations observed in Abidjan and also, but to a lesser extend, in Glanlé, were low. This observation suggests that cystein intake is low in Ivory Coast Republic. The low glutathione reductase activity (Ceballos-Picot et al., 1992; Tessier et al., 1995) and the marginal riboflavin status observed in both groups could also contribute to these low concentrations (Golden and Ramdath, 1987; Kuang, 1991). Indeed, riboflavin deficiency (E GR AC > 1.70) was noted in $74 \%$ of Glanlé subjects and in 34\% of Abidjan residents (Van den berg et al., 1993).

Causes and clinical consequences of the selenium deficiency in Glanlé west mountain Ivory Coast remained to be determined. Although a severe selenium deficiency in Glanlé, selenium supplementation should not be undertaken without iodine supplementation. Indeed, the aggravation of hypothyroxinemia after selenium supplementation is associated with an aggravation of 
hypothyroidism (Goyens et al., 1987; Vanderpas et al., 1993).

\section{References}

Akerboom TPM, Sies H (1981) Assay of glutathione, glutathione disulfide and glutathione mixed disulfides in biological samples. Methods Enzymol 77: 373-382

Arnaud J, Fortis I, Blachier S, Kia D, Favier A (1991) Simultaneous determination of retinol, alpha-tocopherol and beta-carotene in serum by isocratic high-performance liquid chromatography. J Chromat 572: 103-116

Arnaud J, Preziosi P (1994) Réponse du zinc et du sélénium sériques au supplément vitaminique et minéral antioxydant chez des volontaires sains. Eurobiol 28: 29.161-33.165

Bayoumi RA, Rosalki SB (1976) Evaluation of methods of coenzyme activation of erythrocyte enzymes for detection of deficiency of vitamins B1, B2 and B6. Clin Chem 22: 327-335

Ceballos-Picot I, Trivier JM, Nicole A, Sinet PM, Thevenin M (1992) Age-correlated modifications of copper-zinc superoxide dismutase and glutathione-related enzyme activities in human erythrocytes. Clin Chem 38: 66-70

Combs GF (1988) Selenium in foods. Adv Food Res 32: 85-113

Diplock AT (1992) Recent work in Zaïre on seleniumiodine interactions in humans with goiter and in cretins. Biol Trace Elem Res 33: 162-163

Dumont JE, Corvilain B, Contempré B (1994) The biochemistry of endemic cretinism: roles of iodine and selenium deficiency and goitrogens. Mol Cell Endocrinol 100: 163-166

Fairweather-Tait SJ (1997) Bioavailability of selenium. Eur J Clin Nutr 51: S20-S23

Golden MHN, Ramdath D (1987) Free radicals in the pathogenesis of kwashiorkor. Proc Nutr Soc 46: 53-68

Goyens P, Golstein J, Nsombola B, Vis H, Dumont JE (1987) Selenium deficiency as a possible factor in the pathogenesis of myoedematous endemic cretinism. Acta Endocrinol 114: 497-502

Gunzler WA, Kremers H, Flohe L (1974) An improved coupled test procedure for glutathione peroxidase in blood. Z Klin Chem Klin Biochem 12: 444-448

Kölrle J (1995) Thyroid hormone deiodination in target tissues-a regulatory role for trace element selenium? Exp Clin Endocrinol 102: 63-89

Kouamé P, Bellis G, Tebbi A, Gaimard M, Dilumbu I, Assouan A, Roux F, Mayer G, Chastin I, Diarra N, Chaventré A (1998) The prevalence of goitre and cretinism in a population of the West Ivory Coast. Coll Antropol 22: 31-41

Kuang CC (1991) Vitamin E and oxidative stress. Free Radical Biol Med 11: 215-232

Larsen PR, Berry MJ (1995) Nutritional and hormonal regulation of thyroid hormone deiodinases. Ann Rev Nutr 15: 323-352

Levander OA (1982) Selenium: biochemical actions, interactions and some human health implications. In Prasad AS ed. Clinical, biochemical and nutritional aspects of trace elements A.R. Liss, New York, 345-368

Nève J, Thérond P (1991). Le sélénium. In Chappuis P ed. Les oligoélements en médecine et biologie. Lavoisier Tec et Doc, Paris, 425-457

Nève J (1991a). Physiological and nutritional importance of selenium. Experientia 47: 187-193

Nève J (1991b) Methods in determination of selenium states. J Trace Elem Electrolytes Health Dis 5: 1-17

Nichoalds GE, Lawrence JD, Sauberlich HE (1974) Assessment of status of riboflavin nutriture by assay of erythrocyte glutathione reductase activity. Clin Chem 20: $624-628$

Richard MJ (1996) Micronutriments et radicaux libres. Alcoologie 18: 62-66

Tessier F, Margaritis I, Richard MJ, Moynot C, Marconnet $P$ (1995) Selenium and training effects on the glutathione system and aerobic performance. Med Sci Sports Exerc 27: 390-396

Thorling EB, Overvad K, Geboers J (1986) Selenium status in Europe-human data. A multicenter study. Ann Clin Res 18: 3-7

Thurnham DI, Rathakette P (1982) Incubation of NAD(P)H2: glutathione oxidoreductase (EC 1.6.4.2.) with flavin adenin dinucleotide for maximal stimulation in the measurement of riboflavin status. Br J Nutr 48: 459-466

Untoro J, Ruz M, Gross R (1999) Low environmental selenium availability as an additional determinant for goiter in East Java, Indonesia? Biol Trace Elem Res 70: 127-136

Van den Berg H, Heseker H, Lamand M, Sandström B, Thurnham D (1993) Flair concerted action No 10 status paper. Internat J Vit Nutr Res 63: 247-316

Vanderpas JB, Contempré B, Dual NL, Deckx H, Bebe N, Longombé AO, Thilly CH, Diplock AT, Dumont JE (1993) Selenium deficiency mitigates hypothyroxinemia in iodine-deficient subjects. Am J Clin Nutr 57: 271S$275 \mathrm{~S}$

Zimmermann MB, Adou P, Torresani T, Zeder C, Hurrell RF (2000) Effect of oral iodized oil on thyroid size and thyroid hormone metabolism in children with concurrent selenium and iodine deficiency. Eur J Clin Nutr 54: 209-213

Received: February 3, 2001

Accepted: March 10, 2001

Correspondence to: Josiane Arnaud, Département de Biologie Intégrée, CHUG, BP 217, 38043 Grenoble cedex 9, France

e-mail: Josiane.Arnaud@ujf-grenoble.fr 